\title{
On Line Measurement of Organic Iodine During a Severe Nuclear Accident
}

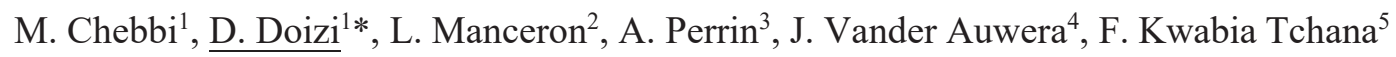 \\ ${ }^{1}$ DEN-Service d'Etude du Comportement des Radionucléides (SECR), CEA, Université Paris-Saclay, France \\ ${ }^{2}$ Ligne AILES, Synchrotron SOLEIL, Gif sur-Yvette, France \\ ${ }^{3}$ Laboratoire de Météorologie Dynamique/IPSL, UMR CNRS 8539, Ecole Polytechnique, Université Paris-Saclay, France \\ ${ }^{4}$ Service de Chimie Quantique et Photophysique, Brussels, Belgium \\ ${ }^{5}$ Laboratoire Interuniversitaire des Systèmes Atmosphériques (LISA), UMR CNRS 7583, Université Paris Est Créteil et Université Paris \\ Diderot, Institut Pierre Simon Laplace, France \\ *denis.doizi@cea.fr
}

\begin{abstract}
A severe nuclear accident may induce a dramatic dissemination of radioactive species into the environment. In that respect, improving the nuclear safety remains an important challenge to improve the society acceptability towards this energy. A solution may consist on implementing robust and reliable measurement systems operating near the Containment Venting Systems (CVS). These devices should be able to provide real time monitoring of the emitted fission products (FPs) in the course of a hypothetical accidental sequence. In the present study, a peculiar attention was devoted to iodine species (namely $\mathrm{CH}_{3} \mathrm{I}$ ) measurement by complementary techniques (photoacoustic spectroscopy and gas chromatography). The most important results will be described here.
\end{abstract}

Index Terms - severe accident, fission products, monitoring, methyl iodide, photoacoustic spectroscopy, gas chromatography.

\section{INTRODUCTION}

After the Fukushima disaster, one of the main objective of the nuclear industry has been to evaluate mitigation strategies to limit the radiological consequences of a severe accident [1]. A significant lack of instrumentation was particularly highlighted during this accident. Indeed, dose rates were only measured twelve days after the event beginning. Hence, an improvement may consist on implementing reliable measurement systems, operating on line at the earliest and closest to the emission source of Fission Products (FPs). The real time monitoring of these FPs as well as their speciation may give valuable information on the core reactor state, resulting in more appropriate severe accident management procedures. Accordingly, the French DECA-PF ANR program was launched from 2013 with the aim to solve these issues.

For instance, the monitoring of radioiodine releases is of specific interest owing to the high radiological impact of its isotopes (namely ${ }^{131} \mathrm{I}$ ), and its ability to exist in volatile forms $\left(\mathrm{I}_{2}\right.$ and $\left.\mathrm{CH}_{3} \mathrm{I}\right)$ [2]. Here, a peculiar attention will be devoted to $\mathrm{CH}_{3} \mathrm{I}$ measurement by complementary techniques. The main objective is to develop specific sensors for the detection of methyl iodide traces. Our methodology is based on a combined approach. On the one hand, some promising sensors (namely micro-GC and miniaturized photoacoustic cells) will be tested.
On the other hand, some innovated materials will be investigated for the selective and reversible capture of $\mathrm{CH}_{3} \mathrm{I}$. Those materials can be used in a pre-concentration stage before the sensor. Finally, some emphasis will also be attempted in order to extrapolate the behavior of these sensors in more representative conditions (temperature, presence of water and other contaminants...).

\section{GAS CHROMATOGRAPHY}

\section{II.1. Principle and optimization of parameters}

A commercial compact device (Agilent $490 \mu G C$ ) has been tested for the detection of methyl iodide. This instrument was already validated within the DECA-PF program, for the detection and quantification of carbon oxides (signature of MCCI occurrence [3]), as well as fission gases namely Xe and $\mathrm{Kr}$, in representative conditions of severe nuclear accident. This apparatus is classically composed of three main parts (Fig. 1): (i) micro-injector (ii) set of four micro-columns and (iii) a micro detector of TCD type. The set of multiple columns affords the possibility to separate and analyze a large panel of gaseous compounds. Giving the polar nature of the investigated molecule, a polar column (PoraPlot $U$ with a length of $10 \mathrm{~m}$ ) was then selected in our case.

At first, preliminary tests were performed in order to optimize the detector response towards $\mathrm{CH}_{3} \mathrm{I}$ detection. For instance, the column temperature was varied from 90 to $150^{\circ} \mathrm{C}$. As stated from the resulted $\mathrm{CH}_{3}$ I chromatograms $(\mathrm{C}=1000$ ppm, Fig. 1), higher temperature leads to a better analysis efficiency in terms of both detection limits and time response.

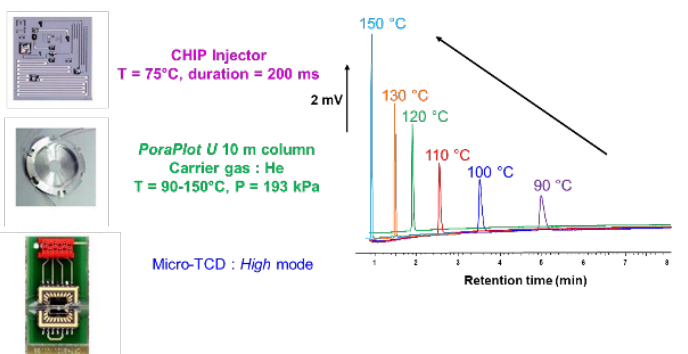

Figure 1: Evolution of $\mathrm{CH}_{3} \mathrm{I}$ peaks as a function of column temperature: $\mathrm{C}_{0}=1000$ $\mathbf{p p m} / \mathbf{N}_{2}$. 
Thus, the column temperature was fixed at $150^{\circ} \mathrm{C}$, in order to have good detection performances (retention time of about 1 min, high signal/noise ratio).

\section{II.2. Detection Performances}

The ability of the optimized $\mu \mathrm{GC}$ was then explored towards the detection of $\mathrm{CH}_{3} \mathrm{I}$ traces. Reproducible concentrations were generated using a certified $\mathrm{CH}_{3} \mathrm{I} / \mathrm{N}_{2}$ bottle (Air Products, 1000 ppm) and Bronkhorst mass-flow controllers $\left(\mathrm{N}_{2}\right.$ balance). A calibration curve was then validated in the range of 5 and 600 ppm (Fig. 2). Hence, a detection limit of $600 \mathrm{ppb}$ was deduced.

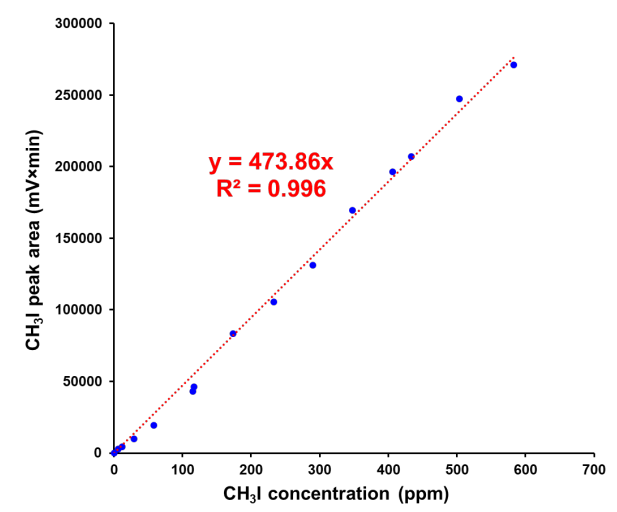

Figure 2: Calibration of $\mathrm{CH}_{3} \mathrm{I}$ signals by Gas Chromatography (Agilent $490 \mu \mathrm{GC}$ ).

On the other hand, the ability of this instrument to detect $\mathrm{CH}_{3} \mathrm{I}$ in the presence of some gaseous species potentially present in accidental conditions $\left(\mathrm{CO}_{\mathrm{x}}\right.$, hydrocarbons, $\mathrm{H}_{2}$ and $\left.\mathrm{Kr}\right)$ has also been validated. It was found that $\mathrm{CH}_{3} \mathrm{I}$ chromatograms were not affected by the presence of these contaminants.

It is worth recalling that $\mathrm{CH}_{3} \mathrm{I}$ concentrations range from 1 to $100 \mathrm{ppb}$ [4]. Thus, a pre-concentration filter stage is required to be implemented before this instrument in order to reach that level. Preliminary works were carried out in order to investigate the retention behavior of some innovated materials towards $\mathrm{CH}_{3} \mathrm{I}$ capture. These works will be more detailed in a forthcoming study.

In the following section, the behavior of an example of absorption spectroscopic technique will be proposed for the first time to detect $\mathrm{CH}_{3} \mathrm{I}$.

\section{PHOTOACOUSTIC SPECTROSCOPY}

\section{III.1. Principle}

Photoacoustic spectroscopy (PA) was found to be one of the most powerful techniques to detect gas traces [5]. The principle of this spectroscopy consists on the excitation of the studied molecule with a light source (QCL: Quantum Cascade Laser as an example) emitting at the wavelength of an absorption line of the molecule. Furthermore, this light source should be modulated at the acoustic frequency of a resonant cavity containing the targeted gas. During the molecules relaxation, kinetic energy exchanges create local periodic variations of the temperature. Thus, an acoustic wave is generated and detected by microphones $[6,7]$.
From the description of these techniques, it can inferred that analysis sensitivity towards a given molecule can be function of several parameters namely: power of the emitted light source, absorption coefficient, microphone sensitivity... [5].

In the case of the studied context, a peculiar attention should be devoted to the selection of the studied absorption line. This latter should be specific for $\mathrm{CH}_{3} \mathrm{I}$ in order to avoid interference phenomena with species present in severe accident conditions (namely water vapor [4]). In addition, the finally selected absorption line should be sufficiently intense in order to reach the detection of methyl iodide traces (1-100 ppb) [4].

In that respect, preliminary FTIR spectroscopic investigations (experimental and theoretical) were performed within the DECA-PF project [8]. It was found that absorption line located at $885 \mathrm{~cm}^{-1}$ is of particular interest for $\mathrm{CH}_{3} \mathrm{I}$ detection thanks to its specificity and its high intensity (cf. Fig. 3).

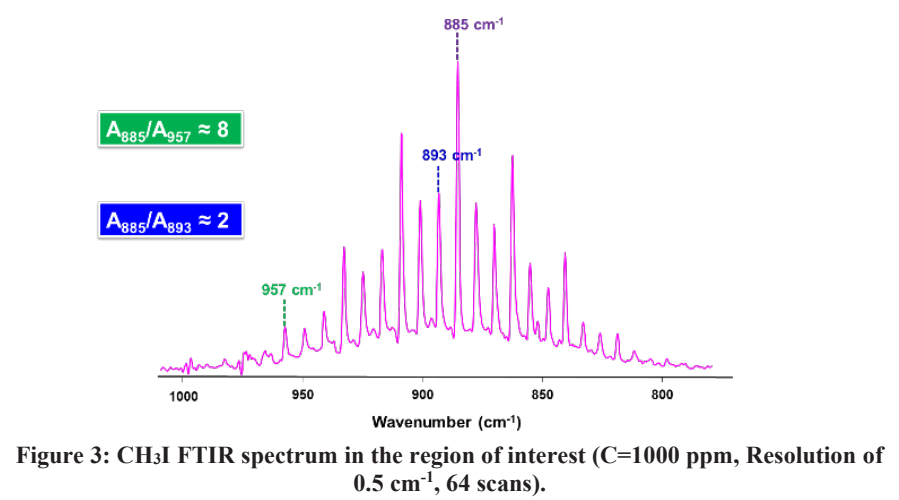

However, it was found that QCL technology associated to this specific wavelength is not available on the market. Hence, we will propose in the next section to discuss the obtained performances of this sensor using other absorption lines.

\section{III.2. Results}

Two complementary setups were tested in order to assess the PA spectroscopy ability towards the detection of $\mathrm{CH}_{3} \mathrm{I}$ traces. On the one hand, a lab-scale configuration (Fig. 4 (A)) was used. It consists on a large setup composed by separate items (continuous $\mathrm{CO}_{2}$ laser, photoacoustic cell, high sensitivity microphone, signal generator...). Despite the complexity and the bulkiness of this apparatus, a very promising detection limit of about $150 \mathrm{ppb}$ was determined experimentally for $\mathrm{CH}_{3} \mathrm{I}$ analysis. On the other hand, a commercial miniaturized detector (Fig. 4 (B)) was tested also for $\mathrm{CH}_{3} \mathrm{I}$ monitoring. This second configuration seems to be more convenient for remote sensing fission products in the studied context. However, this centimeter sized instrument displayed very poor detection performances with a detection limit of $1 \%$ vol.

Several factors can explain these completely different results between the two tested configurations. The most important factor is the laser wavelength used in each apparatus. In the large setup, a continuous $\mathrm{CO}_{2}$ laser with a high power was used (P about $200 \mathrm{~mW}$ ). Furthermore, the selected absorption line was located at $893 \mathrm{~cm}^{-1}$, and presented a rather high intensity $\left(\mathrm{A}_{885} / \mathrm{A}_{893} \approx 2\right.$, Fig. 3). However, a pulsed QCL laser with a very 
low power (about $2 \mathrm{~mW}$ ) was used in the second setup. In addition, the targeted absorption line displayed very low intensity (wavelength of $957 \mathrm{~cm}^{-1}, \mathrm{~A}_{885} / \mathrm{A}_{957} \approx 8$ ) as stated from Fig. 3. Other factors related to the performances of the photoacoustic cell as well as the light source focusing may also probably explain these differences.

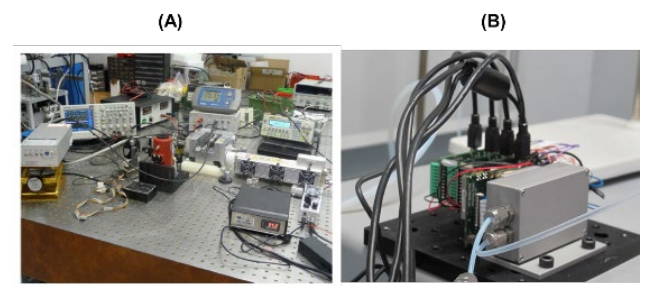

Figure 4: Photos of the tested setups: (A) lab-scale experiment, (B) commercial miniaturized sensor.

\section{CONCLUSIONS AND PERSPECTIVES}

For the first time, the detection performances of different sensors were investigated towards the detection of methyl iodide traces. On the one hand, the tested $\mu \mathrm{GC}$ apparatus was found to display interesting results in terms of detection limit and also of its ability to detect $\mathrm{CH}_{3} \mathrm{I}$ in presence of other compounds. Nevertheless, additional efforts have to be made in order to improve the detection limit using some specific preconcentration filter stages for $\mathrm{CH}_{3} \mathrm{I}$. On the other hand, different results were obtained for PA spectroscopy, between the lab scale experiment and the commercial miniaturized instrument. Those differences were mainly explained by the nature of the light source. These preliminary studies have highlighted the necessity to perform additional tests at an intermediate scale before the ultimate miniaturization of the instrument. These findings are expected in the future to be important towards the enhancement of FPs monitoring in the context of severe nuclear accident.

\section{ACKNOWLEDGMENT}

The DECA-PF project, launched end of 2013 for 3 years, is sponsored by the French government "Investments for the future" program through the grant ANR-11-RSNR-0003 supervised by the French National Research Agency (ANR) under the "Research in Nuclear Safety and Radioprotection" (RSNR) research initiative.

\section{REFERENCES}

[1] International Atomic Energy Agency, Nuclear Safety Review, IAEA/NSR, 2017.

[2] B. Clément, L. Cantrel, G. Ducros, F. Funke, L. Herranz, A. Rydl, G. Weber, C. Wren, OCDE Report., NEA/CSNI/R(2007)/1, 2007.

[3] J.J. Foit, Nucl. Eng. Des. 170 (1997) 73-79.

[4] L.E. Herranz, T. Lind, K. Dieschbourg, E. Riera, S. Morandi, P. Rantanen, M. Chebbi, N. Losch, "State of the Art Report : Technical Bases for Experimentation on Source Term Mitigation Systems." Passam-Theor-T04 [D2.1], 2013.
[5] A. Miklós, P. Hess, and Z. Bozóki, Rev. Sci. Instrum. 72 (2001) 19371955.

[6] J. Rouxel et al. Procedia Engineering 120 (2015) 396-399.

[7] J. Rouxel et al. Sensors and Actuators B 236 (2016) 1104-1110.

[8] A. Perrin, I. Haykal, F. KwabiaTchana, L. Manceron, D. Doizi, G. Ducros, J. Mol. Spectrosc. 324 (2016) 28-35. 